\title{
Effect of temperature on antibiotic properties of garlic (Allium sativum L.) and ginger (Zingiber officinale Rosc.)
}

\author{
Pankaj Sah*, Balqees Al-Tamimi, Najat Al-Nassri and Rahma Al-Mamari \\ Department of Applied Sciences (Applied Biology Section), Higher College of Technology, Al-Khuwair, \\ P. O. Box 74, PC 133, Muscat, Sultanate of Oman.
}

Accepted 26 October, 2012

\begin{abstract}
Garlic and ginger are the two most common herbs used in traditional medicine practice for their antimicrobial activities. Moreover, in many countries, they are also used with boiled food preparations, which can destroy their important medicinal properties. We conducted an agar well diffusion assay with aqueous extracts of garlic and ginger to observe the effect of temperature on their antibiotic properties against three human pathogenic bacteria namely Klebsiella pneumoniae, Escherichia coli and Staphylococcus aureus. The results show that in general, garlic has significantly greater zone of inhibition $($ mean $=23.3 \mathrm{~mm})$ than ginger $($ mean $=19.0 \mathrm{~mm})$ at both, room temperature $\left(26^{\circ} \mathrm{C}\right)(t=4.91 ; \alpha$ $=0.05 ; P<0.01)$ and at higher temperature $\left(100^{\circ} \mathrm{C}\right)$; garlic $($ mean $=15.6 \mathrm{~mm})$; ginger $($ mean $=0 \mathrm{~mm})(t=$ 17.76; df $=2 ; a=0.05 ; P<0.001$ ). On observation, it was found that although higher temperature significantly reduced the antibacterial properties of both plants, nevertheless it affected ginger more ( $t$ $=32.9$, $\mathrm{df}=2 ; \alpha=0.05 ; P<0.001)$ than garlic $(t=11.5, \mathrm{df}=2 ; \alpha=0.05 ; P<0.01)$. From our study, we can conclude that garlic has more prevailing and sustainable antibiotic properties than ginger under normal and higher temperature regimes. We recommend that garlic not only has very promising potential for a broad-spectrum antibiotic drug against many pathogenic bacteria, but also significantly sustains its antibacterial property than ginger even with boiled food preparations. In addition, it can be used as an effective source of natural herbal antibiotics with or without boiling.
\end{abstract}

Key words: Garlic, ginger, medicinal plants, antibiotic properties, naturopathy.

\section{INTRODUCTION}

The augmented usage of antibiotic medicines has given a chance to many bacteria to develop antibiotic resistance in their populations. Besides, the continuous development of resistance to chemotherapeutic agents is increasingly becoming a burning predicament (Abimbola et al., 1993). Consequently, there is an urgent need to unearth the potential antimicrobial materials, especially plants and their parts as they are natural, easily available and do not have any side-effects too. Many plants and their parts are used for various medicinal properties in traditional system of medicine (Khulbe and Sati, 2009).

Various scientists have focus on determining the

\footnotetext{
*Corresponding author. Email: Pankaj@hct.edu.om or drpankaj_sah2002@yahoo.com.
}

antimicrobial activity of plant extracts found in folk medicine, essential oils or isolated compounds such as alkaloids, flavonoids, sesquiterpene lactones, diterpenes, triterpenes or naphtoquinones, among others. Some of these compounds have been isolated or obtained by bioguided isolation after previously detecting antimicrobial activity on the part of the plant. A second block of studies focuses on the natural flora of a specific region or country; the third relevant group of school is made up of specific studies of the activity of a plant or principle against a concrete pathological microorganism (Rios and Recio, 2005). In ethnobotanical literature, both the aerial and root parts have been used as an antiseptic. It has been observed that the leaf part of some plants is effective on cuts and wounds, whereas root powder is being used as antiseptic (Gaur, 1999). Even in traditional medicinal practice, people use many herbs as an 
Table 1. Effect of temperature on the antibacterial activity of Garlic and Ginger.

\begin{tabular}{lcccc}
\hline \multirow{2}{*}{ Test microorganism } & \multicolumn{4}{c}{ Inhibition zone (mm) } \\
\cline { 2 - 5 } & $\begin{array}{c}\text { Garlic aqueous } \\
\text { extract }\left(\mathbf{2 6}^{\circ} \mathbf{C}\right)\end{array}$ & $\begin{array}{c}\text { Garlic aqueous } \\
\text { extract }\left(\mathbf{1 0 0} \mathbf{0}^{\circ} \mathbf{C}\right)\end{array}$ & $\begin{array}{c}\text { Ginger aqueous } \\
\text { extract }\left(\mathbf{2 6}^{\circ} \mathbf{C}\right)\end{array}$ & $\begin{array}{c}\text { Ginger aqueous } \\
\text { extract }\left(\mathbf{1 0 0}^{\circ} \mathbf{C}\right)\end{array}$ \\
\hline Klebsiella pneumoniae (Gram negative) & 26 & 17 & 20 & 0 \\
Escherichia coli (Gram negative) & 23 & 16 & 19 & 0 \\
Staphylococcus aureus (Gram positive) & 21 & 14 & 18 & 0 \\
\hline
\end{tabular}

${ }^{a}$ Data are the average of three experiments.

antibacterial agent.

Garlic (Allium sativum) and ginger (Zingiber officinale) are the two most common plants used in naturopathy. However, in many countries people use these plants along with boiled food preparations, which destroy the plants' important antibacterial agents. The objective of this study was to understand how temperature affects the strength and sustainability of antibiotic properties in garlic and ginger.

\section{MATERIALS AND METHODS}

The study was carried out on common garlic, A. sativum (Alliaceae) and common ginger, Z. officinale Rosc. (Zingiberaceae) plant parts (bulb and rhizome, respectively). A. sativum, the common garlic, has traditional dietary and medicinal applications as an antiinfective agent (Lawson, 1998; Reuter et al., 1996). In vitro evidence of the antimicrobial activity of fresh and freeze-dried garlic extracts against many bacteria (Cavallito and Bailey, 1944; Rees et al., 1993), fungi (Adetumbi et al., 1986), and viruses (Weber et al., 1992) lends support to these applications. On the other hand, $Z$. officinale Rosc. (Zingiberaceae), the common ginger, has a direct inhibitory effect on microbial organisms and it has been used for centuries to fight against bacterial infections (Tan and Vanitha, 2004). In the past few decades, the search for new anti-infection agents has occupied many research groups in the field of ethnopharmacology (Rios and Recio, 2005).

\section{Agar well diffusion assay}

The present agar well diffusion assay was carried out to investigate the effect of temperature on the antibacterial properties of garlic and ginger, since in many countries these herbs are used with boiled food preparations. We assume that a comparison between the antibacterial properties of these two widely used herbs along with increasing temperature would help to use the herbs more effectively. First of all, $215 \mathrm{~g}$ of garlic bulb and ginger rhizome were weighed and the skin was removed with a sharp knife. They were washed at room temperature with distilled and sterilized water. Both herb species were cut into small pieces and ground in blender to obtain juice separately. Afterward, the juice was passed through sterilized filter paper and funnel, and then filtered by vacuum suction pump using Millipore filter paper of $0.45 \mu \mathrm{M}$ pore size. The same process was repeated again and the cut pieces of both herbs were immersed in boiling water $\left(100^{\circ} \mathrm{C}\right)$ for 30 min to see the effect of temperature. Then, the juice was extracted for the heat-treated garlic and ginger.

The agar well assay method was used to explore the antimicrobial activity of both plant parts. Nutrient agar medium was prepared in Petri-plates to grow the test microorganisms. We compared the difference in antibiotic activities of both plant extracts at $100 \mu \mathrm{g} / \mathrm{ml}$ concentration under normal room temperature $\left(26^{\circ} \mathrm{C}\right)$ and at boiling water $\left(100^{\circ} \mathrm{C}\right)$ conditions. The test microorganisms Escherichia coli and Klebsiella pneumoniae (both Gram negative) and Staphylococcus aureus (Gram positive) were obtained from the Department of Applied Sciences (Applied Biology Laboratory), Higher College of Technology (HCT), Al Khuwair, Muscat (Sultanate of Oman). The test bacteria were streaked on the nutrient agar plate in laminar flow under sterilized conditions. A hole of $10-\mathrm{mm}$ diameter was made at the centre of plate by sterilized core borer (Srinivasan et al., 2001) and $100 \mu \mathrm{L}$ of each extract was dropped in the hole using micropipettes. Each plant extract was tested in triplicate to take the average values. All inoculated agar plates were incubated at $37^{\circ} \mathrm{C}$ for $24 \mathrm{~h}$ in the incubator (Khulbe and Sati, 2009). The antibacterial activities of both garlic and ginger were observed from the size of diameter of "zone of inhibition" (ZI), measured in $\mathrm{mm}$.

\section{RESULTS AND DISCUSSION}

A paired $t$-test analysis was performed for the comparison of antibiotic strength and its sustainability and results show that the antibiotic activities of garlic $(A$. sativum) was significantly greater (mean $=23.3 \mathrm{~mm}$ ) under normal room temperature than in boiled conditions $($ mean $=15.6 \mathrm{~mm})$, with a mean difference of $7.6 \mathrm{~mm}$ (Table 1) $(t=11.5, \mathrm{df}=2 ; \alpha=0.05 ; P<0.01)$. The decrease in antibacterial property can be clearly elucidated, as it is a well established verity that the loss of antibacterial activity of natural products by heating may be due to volatilization and/or the physical and chemical changes that occur during heating (Durairaj et al., 2009).

Apart from high temperature (heating), there can be some other reasons for the reduction in antibacterial activity. For example, researchers have given other reasons for reduction in ginger's antibacterial activity like reduction of allicin to diallyl disulfide (Reuter et al., 1996). Similar trends were also observed for the antibiotic activities of ginger (Zingiber officinale) where it was significantly greater under normal room temperature $($ mean $=32.9 \mathrm{~mm})$ than in boiled conditions (mean $=0$ $\mathrm{mm})$, with a mean difference of $19 \mathrm{~mm}$ (Table 1) $(t=$ $32.90, \mathrm{df}=2 ; \alpha=0.05 ; P<0.001)$. In the present study, boiled ginger also lost its antibacterial activity immensely, which can be due to volatilization of its active compounds. When both plant species were treated with boiled water $\left(100^{\circ} \mathrm{C}\right)$ for $30 \mathrm{~min}$, clear reductions in their antibiotic properties were observed. It was observed that 
even in high temperature, garlic ( $A$. sativum) was able to sustain its antibiotic properties. On the other hand, ginger (Z. officinale) totally lost its antibiotic properties against the studied bacterial species.

Increasing temperature deteriorated the antibacterial properties of ginger drastically, but did not affect garlic in similar fashion. In higher temperature of $100^{\circ} \mathrm{C}$, garlic $(A$. sativum) proved to have significantly greater antibiotic activities $(t=17.76 ; \mathrm{df}=2 ; \alpha=0.05 ; P<0.001)$ than ginger ( $Z$. officinale). Comparison between the antibiotic activities of garlic (A. sativum) and ginger ( $Z$. officinale), at both temperatures [under normal room temperature $\left(26^{\circ} \mathrm{C}\right)$ and boiling water temperature $\left.\left(100^{\circ} \mathrm{C}\right)\right]$, the paired sample $t$-test analysis proved that garlic $(A$. sativum) had significantly greater (mean $=22 \mathrm{~mm}$ ) antibacterial properties at $26^{\circ} \mathrm{C}(t=7 ; \mathrm{df}=1 ; \alpha=0.05 ; P<0.05)$ than ginger $(Z$. officinale) $($ mean $=18.5 \mathrm{~mm})$. Even in the increased temperature of $100^{\circ} \mathrm{C}$, garlic $(A$. sativum) had significantly greater (mean $=15 \mathrm{~mm}$ ) antibacterial properties $(t=15 ; \mathrm{df}=1 ; \alpha=0.05 ; P<0.05)$ than ginger (Z. officinale) (mean $=0 \mathrm{~mm}$ ) (Table 1). So, it was found that garlic had stronger and sustainable antibiotic activities than ginger at 26 and $100^{\circ} \mathrm{C}$ temperature $[t=$ $11.5, \mathrm{df}=2 ; \alpha=0.05 ; P<0.01)$ and $(t=17.76 ; \mathrm{df}=2 ; \alpha=$ $0.05 ; P<0.001)$ ], respectively.

Our findings have shown that garlic retained its antibacterial activity even with high temperature treatments. In a recent research, while understanding the effect of temperature on the antibacterial activities of garlic and cinnamon, it was found that in most of the studied bacteria (Bacillus cereus and E. coli) both garlic (A. sativum) and cinnamon (Cinnamomum zeylanicum) retained their antibacterial activity till $120^{\circ} \mathrm{C}$ (Ranjan et al., 2012). Our results support that garlic retained its antibacterial properties even in higher temperature, thus establishing the superiority of garlic's antibacterial activity over ginger in terms of temperature treatment. This also supports the earlier effective antibacterial findings of Indu et al. (2006) that garlic has more potential as an antibiotic herb than ginger. In their study, Indu et al. (2006) found that garlic extract even presented higher diameter of inhibition zones than many known antibiotic drugs like ciprofloxacin, chloramphenicol, tetracycline, streptomycin and nalidixic acid. The antibacterial activity of garlic is reported to be due to the action of allicin or diallyl thiosulphinic acid or diallyl disulphide (Avato et al., 2000). It is postulated that the antibacterial and antifungal properties of garlic juice are due to the inhibition of succinic dehydrogenase via the inactivation of thiol group (Indu et al., 2006).

The present study shows that garlic's antibacterial activity did not cease even up to $100^{\circ} \mathrm{C}$ temperature. In a contemporary research, Ranjan et al. (2012) found that garlic and cinnamon can also be used as natural food preservatives for fishes at room temperature, fried fishes and even deep-fried fishes, since both plants retained their antibacterial activity at very high temperature and the "antibacterial activity index" of garlic and cinnamon was more than 0.5 till $120^{\circ} \mathrm{C}$. The findings of our research are important as they elaborate the effective antibiotic properties of garlic and its importance as a highly potent natural drug source against many bacterial diseases, which can be used even with boiled food preparations also and of course, with its significant antibiotic effect.

\section{ACKNOWLEDGEMENTS}

The authors are highly grateful to the Ministry of Manpower, Sultanate of Oman, Dean, Heads of Science Department and Biology Section, Higher College of Technology, Muscat; for their support during the course of the study. Thanks are also due to all laboratory technicians for helping in the smooth running of the laboratory.

\section{REFERENCES}

Abimbola KA, Obi CL, Alabi SA, Olukoya DK, Ndip RN (1993). Current Status on biotyping antibiogram and plasmid profiles of $E$. coli isolates. East Afr. Med. J. 70:207-210

Adetumbi M, Javor GT, Lau BHS (1986). Allium sativum (Garlic) inhibits lipid synthesis by Candida albicans. Antimicrob. Agents Chemother. 30:499-501.

Avato P, Tursil E, Vitali C, Miccolis V, Candido V (2000). Allylsulfide constituents of garlic volatile oil as antimicrobial agents. Phytomedicine 7(3):239-243.

Cavallito CJ, Bailey JH (1944). Allicin, the antibacterial principle of Allium sativum. I. Isolation, physical properties, and antibacterial action. J. Am. Chem. Soc. 66:1950.

Durairaj S, Srinivasan S, Lakshmanaperumalsamy P (2009). In vitro Antibacterial Activity and Stability of Garlic Extract at different $\mathrm{pH}$ and Temperature. Elect. J. Biol. 5(1):5-10.

Gaur RD (1999). Flora of the District Garhwal North west Himalaya, $1^{\text {st }}$ ed.; Trans Media Publication.

Indu MN, Hatha AAM, Abirosh C, Harsha U, Vivekanandan G (2006). Antimicrobial activity of some of the south-Indian spices against serotypes of Escherichia coli, Salmonella, Listeria monocytogenes and Aeromonas hydrophila. Braz. J. Microbiol. 37(2):153-158.

Khulbe K, Sati SC (2009). Antibacterial Activity of Boenninghausenia albiflora Reichb. (Rutaceae). Afr. J. Biotechnol. 8(22):6346-6348.

Lawson LD (1998). Garlic: a review of its medicinal effects and indicated active compounds. in Phytomedicines of Europe: their chemistry and biological activity. ACS Symposium Series, no. 691. eds Lawson LD, Bauer R. (American Chemical Society, Washington, D.C.). pp. 176-209.

Ranjan S, Dasgupta N, Saha P, Rakshit M, Ramalingam C (2012). Comparative study of antibacterial activity of garlic and cinnamon at different temperature and its application on preservation of fish. Adv. Appl. Sci. Res. 3(1):495-501.

Rees LP, Minney SF, Plummer NT, Staler JH, Skyrme DA (1933). A quantitative assessment of the antimicrobial activity of garlic (Allium sativum). World J. Microb. Biotechnol. 9:303-307.

Reuter HD, Koch HP, Lawson LD (1996). Therapeutic effects and applications of garlic and its preparations. in Garlic. The science and therapeutic application of Allium sativum L. and related species1996. eds Koch HP, Lawson LD (Williams \& Wilkins, Baltimore, Md), pp. 135-212.

Rios JL, Recio MC (2005). Medicinal Plants and Antimicrobial Activity. J. Ethnopharmacol. 100(1-2):80-84.

Srinivasan D, Sangeetha N, Suresh T, Lakshmanaperumalsamy $P$ 
(2001). Antimicrobial activity of certain Indian medicinal plants used in folkloric medicine. J. Ethnopharmacol. 74:217-220.

Tan BKH, Vanitha J (2004). Immunomodulatory and Antibacterial Effects of Some Traditional Chinese Medicinal Herbs: A Review.

Curr. Med. Chem. 11(11):1423-1430.
Weber ND, Anderson DO, North JA, Murray BK, Lawson LD, Hughes BG (1992). In vitro virucidal effects of Allium sativum (garlic) extract and compounds. Planata Med. 58:417-423. 